\title{
Case Report: Lumbal Spine Compression Fractures in Spondylolisthesis Modified Chairback Orthosis
}

\author{
Serap ALSANCAK, Senem GÜNER, Haydar ALTINKAYNAK \\ Ankara Üniversitesi Sağlık Hizmetleri Meslek Yüksekokulu, Ankara \\ sguner@ankara.edu.tr
}

\begin{abstract}
Lumbosacral orthoses are used commonly as a conservative treatment method in spondylolisthesis and stable spine compression fractures. Modified chairback orthosis, which developed by 4 forces on the basis of biomechanical principles, was applied with the spondylolisthesis to the 74 year old case who has a compression fracture. Effect of orthosis was assesed by comparing lumbosacral region range of motion and effect to the daily activities was assessed by comparing rigid LSO. As a result, modified chairback orthosis allowed $2^{\circ}-7^{\circ}$ motion at lumbosacral region and reduced the pain. Orthosis did not cause any difficulty in daily activites except putting on and off.
\end{abstract}

Keywords: LSO, chairback orthosis, spondylolisthesis, compression fracture, spinal stenosis.

\section{Vaka Sunumu: Spondilolistezis Lumbal Spinal Kompresyon Kırığı Modifiye Chairback Ortezi}

\begin{abstract}
Özet
Lumbosakral ortezler spondilolistezis ve stabil omurga kompresyon kırıklarında konservatif bir tedavi metodu olarak kullanılır. Modifiye chairback ortezi, biomekanik prensibler temelinde olarak 4 kuvvet prensibine göre geliştirildi ve 74 yaşında, geriatrik, kompresyon kırığı olan vakaya uygulandı. Ortezin etkisi lumbosakral bölge hareket açıklığı ve günlük yaşam aktivitelerine etkisi incelenerek ve rijid LSO ile karşılaştırılarak değerlendirildi. Sonuç olarak, modifiye chairback ortezi lumbosakral bölgede $2^{\circ}-7^{\circ}$ lik harekete izin verdi ve ağrıyı azalttı. Ortez günlük aktivitelerde giyme ve çıkarma zorluğuna sebep olmadı.
\end{abstract}

Anahtar Kelimeler: LSO, chairback ortezi, spondilolistezis, kompresyon kırıkları, spinal stenoz.

\section{Introduction}

At spinal fractures, stabilization of fractured area is an important factor on deciding the treatment method. General consepts are conservative at stable fractures, surgical treatment at non-stable fractures. Spine compression fractures are stable fractures, where vertebras are wedged and hyperflexion forces are formed (McEvoy et al., 1985, Chan et al.,1993, Cantor et al., 1993, Weinstein 
et al., 1988). Knight et.al stated that conservative treatment methods are convenient on cases when single-level and more than fractures, tightness at spinal channel is less than $20^{\circ}$, kyphosis angle is less than $20^{\circ}$, loss of anterior height is less than $20^{\circ}$ and there is no neurologic deficiency (Knight et al., 1987). Positive outcomes of conservative treatment approach on stable compression fractures, where being wedged is less than $30^{\circ}$, are mentioned in general (Tonbul et al., 2008, Tezer et al., 2005). At degenerative spondylozisthesis is often recommended as a conservative treatment method. Epidural steriod injection and physical therapy are used to reduce the symptomatic complaints (Grobler et al., 1993). Willner reported a reduction of pain on 6 of 7 cases with Boston Orthosis treatment (Willner, 1985). Prateepavanich et.al pointed out the positive impact of lumbosacral orthosis on 21 cases who have symptomatic lumbal spinal stenosis diagnosis (Prateepavanich et al., 2001).

Lumbosacral orthosis (LSO) and abdominal corsets are preferred at conservative and postoperative lumbar region problems and painful waists. While abdominal corsets have effective role on prevention of lumbar region injuries with its ergonomic approach, LSOs are used in protection of region after surgery; in cases when conservative treatment is preffered according to the conformance of the purpose, used for either one of the correction, support or immobilization functions or two of them, thus provide protection region mechanics and continuation of the treatment process. On the fracture regarding with lumbar vertebra, in case of sliding, lumbar region is supported and motions are controlled with custom-fabricated orthosis as per biomechanical principles (Lantz et al., 1986, Buchalter et al.,1988, van Poppel et al., 2000, Krag et al., 2003, McGill et al., 1993, Koes et al 1994, McGill et al., 1998, Jellema et al., 2001, van Duijvenbode et al., 2008). There are various types of LSOs and these can be categorized to 4 groups according to their material types and effects. Fabricated with flexible, rubber or neoprene material, non-elastic or fabric material, semi flexible; plastic material and rijid; metal or hard plastic (Grew and Deane, 1982). Rigid orthosis restrict spinal movement more than flexible LSOs (Parnianpour et al., 1990). Parnianpour attracted attentions to the fact that flexible orthosis are no restrict on spinal movements.

Jegede et.al assessed flexion-extension, lateral flexion and rotation range of motion (ROM) by using electrogoniometer, which examines the effects of flexible, semi-flexible and rigid orthosis on lumbar region movements during activities of daily life (ADL) in their study (Jegede et al., 2011). They recorded $24.1 \%$ reduction active range of motion (ROM) at sagittal plane movement with flexible corset usage, $46.1 \%$ with semi flexible corset and $64.7 \%$ with rigid corset. They stated that there is no identical difference between rigid and semi-flexible corset, there were differences only in couple of activities between semi flexible and flexible orthosis; however, considerable restriction was provided at rigid orthoses.

Spinal orthoses generally composed of sternal, abdominal and paraspinal supports, thoracic and pelvic bands with in case of necessity midaxillar supports. Thus, body's flexion, extension, lateral flexion and rotational movements are tried to be controlled. Differences of basic orthoses, which are used at pathologies regarding with lumbar region, are as follows: At chairback type orthosis, two hard or semi flexible paraspinal bars are connected with flat pelvic and thoracic bands. This orthosis, which is composed of metal material, controls sagittal plane movement in conformance with three point principle. Additionally, there are lateral bars at Knight type LSO, which controls anteroposterior, lateral movements. Thereby, restriction is provided at lateral flexion. Control of movement is provided with three point principle. At Williams LSO type, which provides movement control at posterior and lateral direction, there are pelvic and thoracic bands, lateral bars, and oblique bars. Oblique bars provide structural integrity. Thoracic bands and lateral bars are mobile. This type allows lumbosacral flexion while restricts extension. This orthosis, which was defined by Williams in order to utilize in spondylolisthesis treatment in 1937, is still in use today. On the other hand, Raney's plastic jacket, that aims to fully control the lumbosacral anterior, posterior and lateral movement, is planned to restrict the movement on various planes (Hsu et al.,2008, Shur and Michael, 2002, Alsancak, 2009). However, no studies were encountered about the case when there are both fractures at different 
vertebras at lumbar region and spondylolisthesis, and the biomechanical solution of this case on orthosis.

This study was carried out in order to discuss the properties of build up modified chairback orthosis for a conservative treatment with semi-flexible LSO case having compression fractures as well as spondylolisthesis and identify the differences relative to rigid LSO in terms of moving ease and activities of daily life.

\section{Case Report}

Case is 74-year old woman, who is $58 \mathrm{~kg}$ weight and $150 \mathrm{~cm}$ height with a diagnosis of $\mathrm{L}_{1}$ compression fracture lumbar spinal stenosis and $\mathrm{L}_{5}-\mathrm{S}_{1}$ grade I spondylolistesis (Figure1), case applied our laboratory for manufacturing a custom-fabricated semi-flexible LSO. At her physical examination, it was observed that body movements are painful and limited; also she walks with cane support.
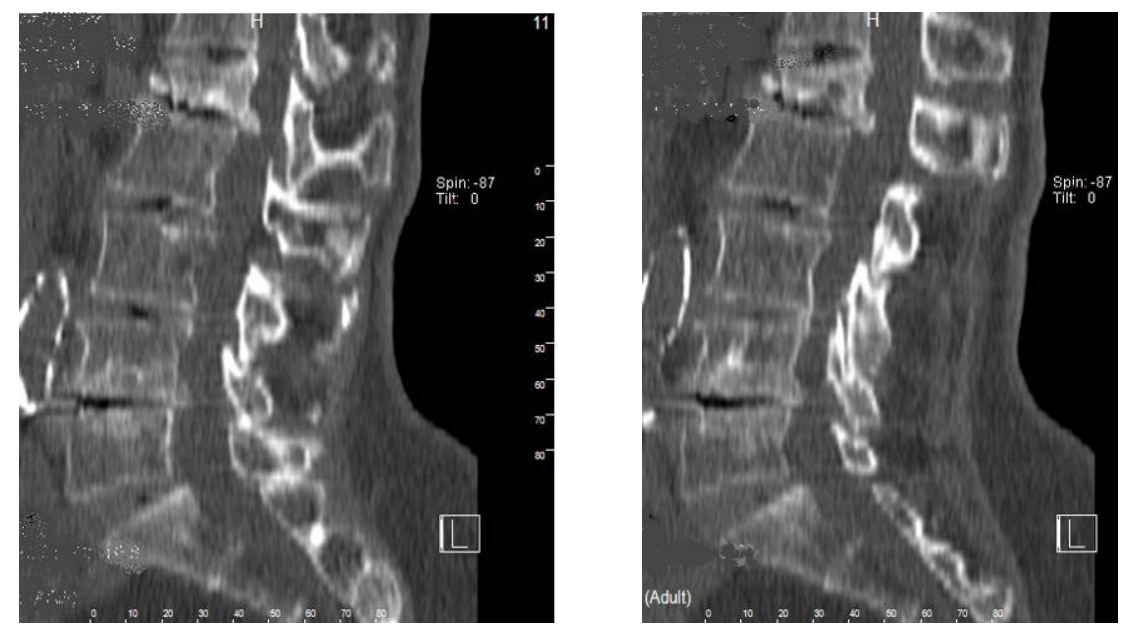

Figure 1. Computerized tomography image of lumbar vertebras.

Plaster cast measure was taken from our patient. On the positive cast rectification developed, three dimensional four corrective forces were designed which conform to existing pathologies (Figure 2). At positive cast rectification, abdominal region was divided into three equal regions. As middle region was planned as confronting region of $\mathrm{F}_{3}$, no rasping was applied to this region. On other upper and lower regions, required degree of rasping was done in order to form $F_{1}$ and $F_{2}$ forces.
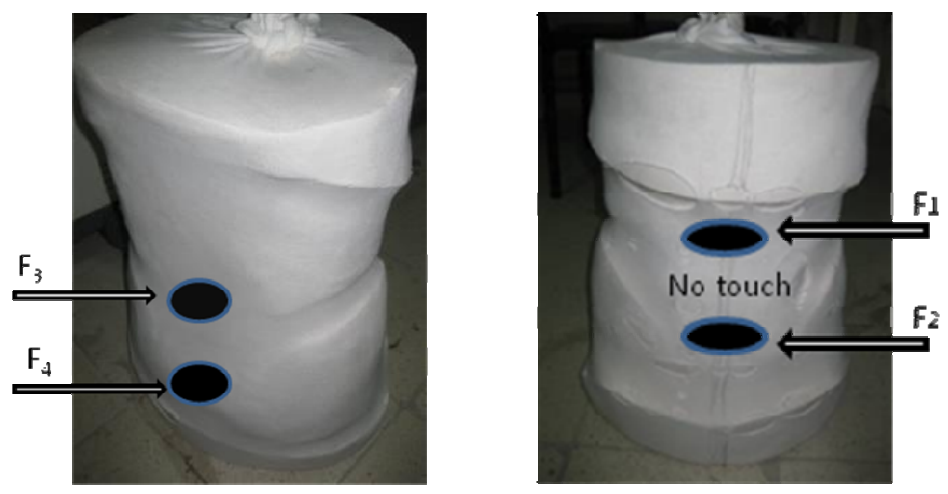

Figure 2. Positive cast rectifications 
Planned in the form of a chairback modification, this semi rigid orthosis was manufactured from semi-flexible material made of $6 \mathrm{~mm}$ thick high density polyethylene. Thereby, easy deformation of orthosis, and being affected from reactive forces occurred in different planes were reduced. Unlike from chairback orthosis, this orthosis is composed of two parts (Figure 3). First part was located on abdominal region at anterior. Xiphoid process was held large at subcostal region lying piece between symphisis pubis and the upper side costas were supported on both sides with a gentle inclination and the bottom side, appropriate beds were provided and pressure was applied iliac crest. It was aimed to extend to the xiphoid process and provide local hyperextension by means of force formed at region. Second part was located on paraspinal muscles. Designed structure surrounding the pelvic band's sacroiliac joint and supporting muscles with the transverse section, which lies beneath the posterior part of scapula, was extended to the lateral midaxillary region. At the designed modified chairback orthosis, from anterior, $F_{1}$ force was applied under xiphoid process as hyperextension force, and $F_{2}$ above symphisis pubis as antilordotic force; from posterior $\mathrm{F}_{3}$ force was applied at region, where the compression fracture exists, as fracture force by means of a band which surrounds from channel inside corset and $\mathrm{F}_{4}$ above gluteal as sacral force. Up and down movement of the corset was prevented by applying pressure on subcostal and supra iliac crest. Anterior abdominal and posterior paraspinal pieces were connected each other with 3 pairs of fabric colons (Figure 4).

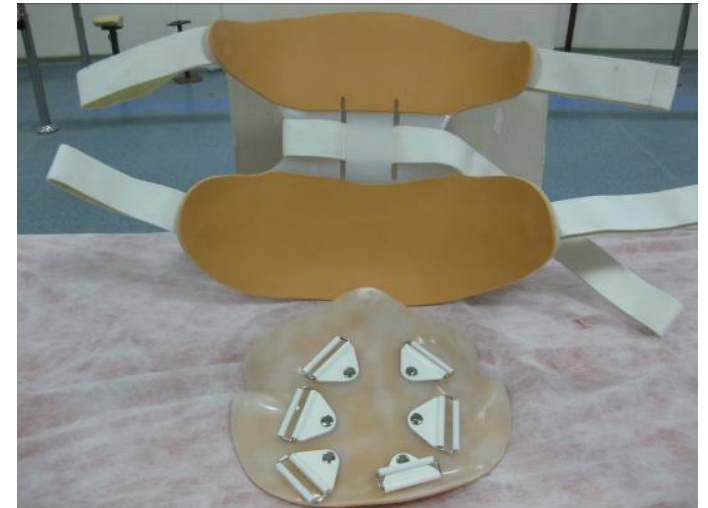

Figure 3. Abdominal and paraspinal parts of modified chairback orthosis

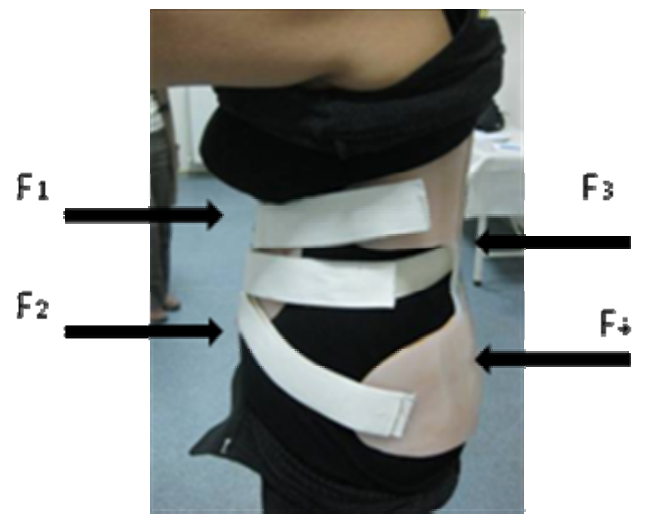

Figure 4. Corrective forces of modified chairback orthosis

$\mathrm{F}_{1}$ : Hyperextension force

$\mathrm{F}_{2}$ : Antilordotic force

$\mathrm{F}_{3}$ : Fracture force

$\mathrm{F}_{4}$ : Sacral force
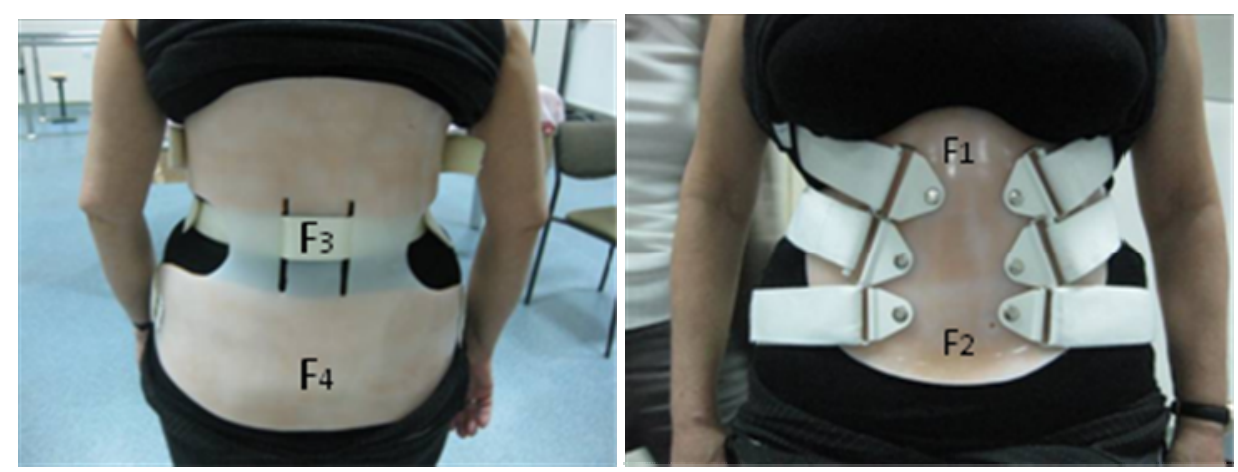

Figure 5. Anterior and posterior view of modified chairback orthosis. 
While upper oblique bands are located approximately with $45^{\circ}$ angle, connected with the paraspinal part's section, which extends transverse at thoracic region. At the oblique planning of upper bands, it was aimed to distribute and reduce the pressure on upper lumbar vertebras. Again at the front, convex structure of abdominal cavity through the middle line was planned to neutralize the $\mathrm{F}_{3}$ force that is completely applied on $\mathrm{L}_{1}$ from posterior with middle colon and aims to direct compression stress on vertebra's anterior element to vertebra's posterior element. At the posterior part's pelvic surrounding section, anterior part is connected by a lower oblique band, which extends from two sides. While upper section of the abdominal part was forming posterior directed hyperextension effect by means of $F_{1}$ force, lower section, lower piece of the part tried to form a reducing effect for lumbar lordosis and $\mathrm{L}_{5}$ spondylolisthesis by means of $\mathrm{F}_{2}$ force (Figure 5). Interior surface of corset was covered with $6 \mathrm{~mm}$ pedilin except surface area of $F_{3}$ force. Thereby, it was aimed to increase the corrective effect formed by tension applied over semi flexible plastic. Hole was not opened in order not to reduce the endurance of the modified chairback orthosis, not to allow excess flexibility. Required air circulation was provided by vast amount of open area on orthosis itself.
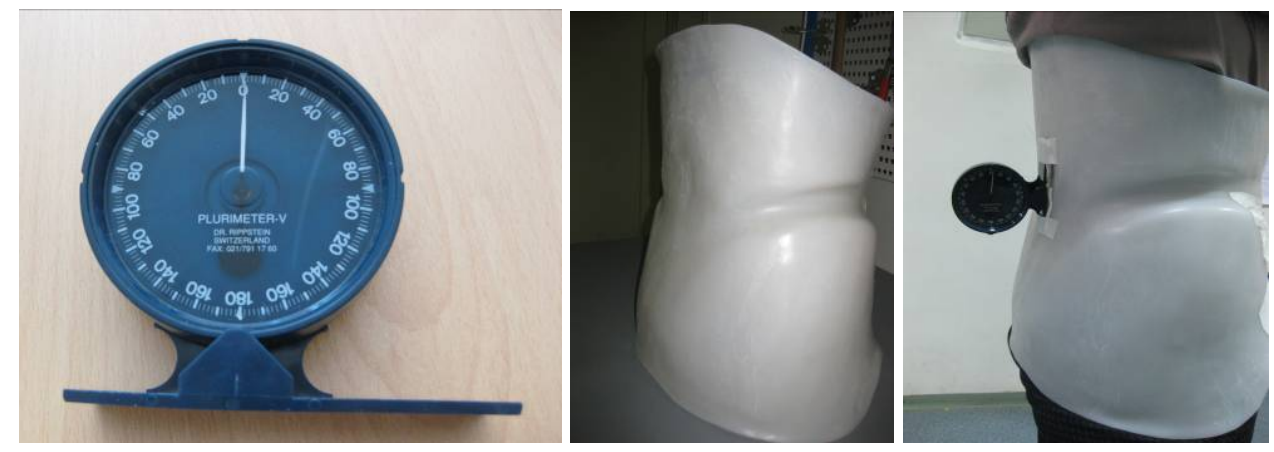

Figure 6. Plurimeter, plastic body-jacket type LSO and lumbosacral ROM measurement.

In order to identify the differences of this orthosis in terms of movement ability and ADL, to compare with jacket type rigid LSO, which is composed of same width plastic material, high density thermoplastic was covered over same positive model (Figure 6). It was determined with the measurements done by plurimeter that when compared with rigid LSO, modified chairback orthosis we improved allowed flexion, extension and lateral flexion to a certain degree (Table 1). When the effects of our orthosis on ADL were analyzed, activities like taking an object from ground, wearing socks were done much more difficult with rigid LSO. Visual analog scale (VAS) assessment, it was stated that orthosis we improved was effective in reducing pain at lumbosacral region. Difficulty in usage during activities such as toilet in rigid LSO drew attention. Although our orthosis comes forward in ease of movement and ADL, being not practical during wearing and removal due to redundancy of the bands was identified as a disadvantage.

Supporting lumbosacral region, restricting movement to a certain degree, increasing lordosis at posteroproximal, reducing lordosis at posterodistal, being able to distribute abdominal pressure on periphery over lumbar vertebras, are the main advantages of orthosis. In addition, suspension problem of chairback orthosis was not observed in our modification and the approaches of additional gluteal band application to prevent slipping of orthosis when case sits, double band or pelvic corset application, which surrounds pelvic completely, were not needed.

In addition to Knight, Williams and Raney LSOs, which encloses lumbar region and known that they are very effective in restricting lumbosacral region movements, it has been agreed on applicability of modified chairback orthosis, when forming some mechanical effects, which do not require too much restriction, and states when one region is positioned at hyperextension while another region is needed to direct to flexion. 
Table 1. Assessment of lumbosacral range of motion.

\begin{tabular}{|l|c|c|}
\hline \multicolumn{1}{|c|}{ ROM } & $\begin{array}{c}\text { Modified Chairback Orthosis } \\
\text { (Semi-flexible LSO) }\end{array}$ & $\begin{array}{c}\text { Plastic Body-Jacket Type } \\
\text { (Rjgid LSO) }\end{array}$ \\
\hline Flexion & $7^{\circ}$ & $3^{\circ}$ \\
\hline Extension & $2^{\circ}$ & $0^{\circ}$ \\
\hline Lateral flexion & $4^{\circ}$ & $0^{\circ}$ \\
\hline
\end{tabular}

Table 2. Assessment of activities of daily life.

\begin{tabular}{|c|c|c|}
\hline ADL & $\begin{array}{c}\text { Modified Chairback } \\
\text { Orthosis } \\
\text { (Semi-flexible LSO) }\end{array}$ & $\begin{array}{c}\text { Plastic Body-Jacket } \\
\text { Type } \\
\text { (Rigid LSO) }\end{array}$ \\
\hline $\begin{array}{c}\text { Switch to a sitting position } \\
\text { To reach something in a sitting position from } \\
\text { anterior }\end{array}$ & Easy & Moderate \\
\hline $\begin{array}{c}\text { To reach something in a sitting position from } \\
\text { lateral }\end{array}$ & Easy & Moderate \\
\hline Hand washing when standing & Easy & Easy \\
\hline Lifting an object on the ground & Moderate & Easy \\
\hline Walking & Easy & Easy \\
\hline Ascending a stair & Easy & Hard \\
\hline Descending a stair & Easy & Easy \\
\hline Toilet utilization & Easy & Available \\
\hline Dressing - undressing & Hard & Not available \\
\hline Sweating & &
\end{tabular}

ADL: Activities of daily life

\section{References}

Alsancak S. 2009. Ortez.Hatipoglu. Pres, 129-131.

Buchalter D, Kahanovitz N, Viola K, Dorsky S, Nordin M. 1988. Threedimensional spinal motion measurements. Part 2: A noninvasive assessment of lumbar brace immobilization of the spine. J Spinal Disord, 1(4),284-286.

Cantor JB, Lebwohl NH, Garvey T, Eismont FJ. 1993. Nonoperative management of stable thoracolumbar burst fractures with early ambulation and bracing. Spine, 18,971-6.

Chan DP, Seng NK, Kaan KT. 1993. Nonoperative treatment in burst fractures of the lumbar spine (L2-L5) without neurolojic deficits. Spine, 18,320-5.

Grobler LJ, Robertson PA, Novotny JE, et al. 1993. Etiology of spondylolisthesis: assessment of the role played by lumbar facet joint morphology. Spine, 18,80-91.

Grew ND, Deane G. 1982. The physical effect of lumbar spinal supports. Prosthet Orthot Int;6.79-87.

Hsu DJ, Michael WJ, Fisk RJ. 2008. AAOS Atlas of Orthoses and Assistive Devices Fourth Edition, Mosby. Chapter 8., p.113-124.

Jegede KA, Miller CP, Bible JE, Whang PG, Grauer JN. 2011. The effects of three different types of Orthoses on the Range of Motion of the Lumbar Spine During fifteen Activities of daily living. Spine, Feb.24. 
Jellema P, van Tulder MW, van Poppel MN, Nachemson AL, Bouter LM. 2001. Lumbar supports for prevention and treatment of low back pain: asystematic review within the framework of the Cochrane Back Review Group. Spine, 26(4), 377-386.

Knight RQ, Stornelli DP, Chan DPK, Devanny JR, Jackson KV. 1987. Comparison of operative versus nonoperative treatment of lumbar burst fractures. Clin Orthop, 187,163-170.

Koes BW, van den Hoogen HMM. 1994. Efficacy of bed rest and orthoses on low back pain: a review of randomized clinical trials. Eur J Phys Med Rehabil, 4,86-93.

Krag MH, Fox MJ, Haugh LD. 2003. Comparison of three lumbar orthoses using motion assessment during task performance. Spine, 28(20), 2359-2367.

Lantz SA, Schultz AB. 1986. Lumbar spine orthosis wearing. I. Restriction of gross body motions. Spine, $11(8), 834-837$.

McEvoy RD, Bradford DS. 1985. The management of burst fractures of the thoracic and lumbar spine. Experience in 53 patients. Spine, 10,631-7.

McGill SM. 1993. Abdominal belts in industry: a position paper on their assets, liabilities and use. Am Ind Hyg Assoc J, 54(12),752-754.

McGill SM. 1998. Update on the use back belts in industry: more data - same conclusion. In The Occupational Ergonomics Handbook Edited by:Karwowski W, Marras WS. CRC, 1353-1358.

Parnianpour M, Franceschini G, Torre D, Yuen L. 1990. The effects of lumbar support on the isoinertial strength and endurance performance of normal healthy males. In: Abstracts of the International Society for the Study of the Lumbar Spine, 61.

Prateepavanich P, Thanapipatsiri S, Santisatisakul P, et al. 2001. The effectiveness of lumbosacral corset in symptomatic degenerative lumbar spinal stenosis. J Med Assoc Thai, 84,572-576.

Shur GD, Michael JW. 2002. Prosthetics and Orthotics, 2nd ed. Pretice Hall Pres, 203-227.

Tezer M, Erturer RE, Ozturk C, Ozturk I, Kuzgun U. 2005. Conservative treatment of fractures of the thoracolumbar spine. International Orthopadedics, 29,78-82.

Tonbul M, Yilmaz MR, Ozbaydar MU, Adas M, Altan E. 2008. Long-term results of conservative treatment for thoracolumbar compression fractures. Acta Orthop Traumatol Turc, 42(2),80-83.

Weinstein JN, Collalto P, Lehmann TR. 1988. Thoracolumbar 'burst' fractures treated conservatively: a longterm follow-up. Spine, 13,33-8.

Willner S. 1985. Effect of a rigid brace on back pain. Acta Orthop Scand, 56,40-42.

van Poppel MN, de Looze MP, Koes BW, Smid T, Bouter LM. 2000. Mechanisms of action of lumbar supports: a systematic review. Spine, 25(16),2103-2113.

van Duijvenbode IC, Jellema P, van Poppel MN, van Tulder MW. 2008. Lumbar supports for prevention and treatment of low back pain. Cochrane Database Syst Rev. CD001823. 
